\title{
Impact of resident involvement in neurosurgery: an analysis of 8748 patients from the 2011 American College of Surgeons National Surgical Quality Improvement Program database
}

\author{
Seokchun Lim, BSE, ${ }^{1}$ Andrew T. Parsa, MD, PhD, ${ }^{2}$ Bobby D. Kim, MS, ${ }^{1}$ Joshua M. Rosenow, MD, ${ }^{2}$ \\ and John Y. S. Kim, MD ${ }^{3}$
}

${ }^{1}$ Chicago Medical School, Rosalind Franklin University of Medicine and Science, North Chicago; and Departments of ${ }^{2}$ Neurosurgery and ${ }^{3}$ Surgery, Northwestern University, Feinberg School of Medicine, Chicago, Illinois

\begin{abstract}
OBJECT This study evaluates the impact of resident presence in the operating room on postoperative outcomes in neurosurgery.
\end{abstract}

METHODS The authors retrospectively reviewed the American College of Surgeons National Surgical Quality Improvement Program (ACS-NSQIP) and identified all cases treated in a neurosurgery service in 2011. Propensity scoring analysis and multiple logistic regression models were used to reduce patient bias and to assess independent effect of resident involvement.

RESULTS Of the 8748 neurosurgery cases identified, residents were present in 4529 cases. Residents were more likely to be involved in complex procedures with longer operative duration. The multivariate analysis found that resident involvement was not a statistically significant factor for overall complications (OR 1.116, 95\% CI 0.961-1.297), surgical complications (OR 1.132, 95\% Cl 0.825-1.554), medical complications (OR 1.146, 95\% Cl 0.979-1.343), reoperation (OR 1.250, 95\% Cl 0.984-1.589), mortality (OR 1.164, 95\% Cl 0.780-1.737), or unplanned readmission (OR 1.148, 95\% Cl 0.946-1.393).

CONCLUSIONS In this multicenter study, the authors demonstrated that resident involvement in the operating room was not a significant factor for postoperative complications in neurosurgery service. This analysis also showed that much of the observed difference in postoperative complication rates was attributable to other confounding factors. This is a quality indicator for resident trainees and current medical education. Maintaining high standards in postgraduate training is imperative in enhancing patient care and reducing postoperative complications.

http://thejns.org/doi/abs/10.3171/2014.11.JNS1494

KEY WORDS American College of Surgeons National Surgical Quality Improvement Program; resident involvement; neurosurgery; postoperative complications

$\mathrm{R}$ ESIDENCY has the dual mission of both educating future physicians and providing invaluable medical services to both hospitals and patients; thus it is held to the highest standard and is regarded by academic medical centers as a major responsibility. Resident education, however, has been a subject of great scrutiny by patients. A survey of 200 surgical inpatients by Cowles et al. demonstrated that one-third of patients did not wish to have residents involved in any part of their operation, and most of the remaining patients strongly preferred that residents participate only in minor procedures. ${ }^{9}$

The impact of resident involvement on surgical outcomes has been widely investigated in general and vascular surgery service, which demonstrated a modest increase

ABBREVIATIONS ACS-NSQIP = American College of Surgeons National Surgical Quality Improvement Program; ASA = American Society of Anesthesiologists; DVT = deep venous thrombosis; HIPAA = Health Insurance Portability and Accountability Act; RBCs = red blood cells; RVU = relative value unit; SSI = surgical site infection. SUBMITTED January 13, 2014. ACCEPTED November 24, 2014.

INCLUDE WHEN CITING Published online January 23, 2015; DOI: 10.3171/2014.11.JNS1494.

DISCLOSURE The authors report no conflict of interest concerning the materials or methods used in this study or the findings specified in this paper. The ACS-NSQIP and the hospitals participating in that database are the source of the data used herein; they have not verified and are not responsible for the statistical validity of the data analysis or the conclusions derived by the authors. 
in complication rates and prolonged operative duration, although no significant differences were found in clinically relevant morbidities or mortality. ${ }^{1,24,34,38,39,41,46}$ However, in the field of neurosurgery, no study has comprehensively examined the relationship between resident participation and surgical outcomes at the multiinstitutional level.

The American College of Surgeons National Surgical Quality Improvement Program (ACS-NSQIP) is a national, validated, risk-adjusted, and prospectively maintained surgical outcomes registry that contains more than 240 clinical variables including preoperative patient characteristics, intraoperative variables, and 30-day postoperative outcomes. Given that the current database contains a wide array of clinical information from more than 440,000 patients, it is uniquely poised to perform high-powered retrospective studies and to help definitively answer whetherand to what degree-resident involvement impacts postoperative outcomes in neurosurgery.

\section{Methods \\ Data Acquisition}

Details of the NSQIP database have been described previously. ${ }^{2,3}$ In 2011, the NSQIP only applied to medium and large hospitals with at least 100 beds. To ensure data reliability, clinical reviewers complete comprehensive training programs, and the NSQIP conducts interrater reliability audits in participating hospitals. Most recently, the interobserver disagreement was calculated at $1.96 \%{ }^{44}$ All patient information is de-identified to comply with the Health Insurance Portability and Accountability Act of 1996 (HIPAA) and the ACS-NSQIP participant user agreement. De-identified patient information is freely available to all institutional members who comply with the ACS-NSQIP Data Use Agreement. (The Data Use Agreement implements the protections afforded by the HIPAA and the ACS-NSQIP Hospital Participation Agreement.)

We retrospectively reviewed the NSQIP database to identify all cases that were treated in a neurosurgery service in 2011. Of the 17,931 cases identified, 9183 cases without resident data or relevant clinical variables (demographics, comorbidities, operative details, postoperative outcomes) were excluded, leaving a total of 8748 cases for analysis. This was a necessary step because our analysis (i.e., propensity scoring, multivariate analysis) could not account for the cases with missing variables. Included cases were subdivided into two cohorts based on resident presence in the operating room (Attending alone vs Attending and Resident in operating room). Primary outcomes of interest included overall/surgical/medical complications, reoperation, mortality, and unplanned readmission.

Overall complication was defined as any surgical or medical complication within 30 days of surgery. Surgical complications consisted of surgical site infection (SSI), wound dehiscence, and graft/prosthesis failure. Medical complications included pneumonia, unplanned intubation, pulmonary embolism, mechanical ventilation $>48$ hours, acute renal failure, urinary tract infection, stroke, coma, peripheral nerve injury, cardiac arrest, myocardial infarction, blood transfusion $>4 \mathrm{U}$ within 72 hours of operation, deep venous thrombosis (DVT), and sepsis/septic shock. Reoperation was defined as return to the operating room within 30 days of the index procedure for surgical intervention of any kind. Mortality was recorded if death occurred within 30 days of the operation. The NSQIP defines unplanned readmission as returning to the same or a different hospital within 30 days of the principal operation due to causes that are "likely related to the index procedure."11

Demographic variables included age, body mass index, sex, and race. Analyzed comorbidities included diabetes, current smoking, dyspnea, dependent functional health status prior to surgery, ventilator dependence (any ventilator-assisted respiration $>48$ hours prior to surgery), chronic obstructive pulmonary disease, congestive heart failure, hypertension requiring medication, acute renal failure, current dialysis requirement, disseminated cancer, preoperative open wound/wound infection, steroid use for chronic condition, $>10 \%$ weight loss within 6 months prior to surgery, bleeding disorder (risk for excessive bleeding requiring hospitalization due to a deficiency of blood clotting elements), and systemic sepsis. Perioperative details included preoperative transfusion (recorded if a patient received $>4 \mathrm{U}$ packed red blood cells [RBCs] within 72 hours of surgery), emergency case, wound classification, American Society of Anesthesiologists (ASA) class, total operative time, and total work relative value unit (RVU).

\section{Risk Adjustment}

Patient demographic profiles, comorbidities, and perioperative details were used for risk adjustment. Total RVUs were used to control for the differences in procedural complexity. ${ }^{15,17,18}$

To calculate the predicted probability of resident presence in the operating room, propensity scoring analysis was performed using demographics, comorbidities, and perioperative details. ${ }^{12,26}$ The propensity score indicates the probability of resident presence in the operating room based on input variables. Specifically, the propensity score of 0 represents the lowest probability of resident involvement, and 1 represents the maximum probability of resident involvement in the case. The calculated propensity score was then incorporated into the logistic regression model as an adjustment variable to balance confounding variables and reduce bias between the two cohorts. ${ }^{12}$

\section{Statistical Analysis}

Descriptive and comparative statistics of demographics, comorbidities, operative details, and postoperative complications were analyzed for all patients. For categorical variables, Pearson's chi-square or Fisher's exact test was performed where appropriate. For continuous variables, the 1-way ANOVA test was used.

We then used multivariate regression analysis to estimate the impact of resident involvement on 30-day outcomes. A total of 6 regression models were constructed, which independently assessed each outcome of interest: overall complication, surgical complication, medical complication, reoperation, mortality, and readmission. Variables to be included in the regression analysis (i.e., potential confounders) were selected from patient comorbidities 
and operative characteristics using the selection criteria of $\mathrm{n}>9$ and $\mathrm{p}<0.2$ by using a series of univariate analyses between an outcome and each of the patient comorbidities (e.g., overall complication vs diabetes). Candidate variables qualifying the selection criteria and calculated propensity scores were included in the regression model for overall complication as adjustment variables. These steps were independently performed for all 6 multivariate analyses. This specific selection criterion was used to capture as many potential risk factors as possible without compromising the validity of regression models. ${ }^{35}$

Receiver operating characteristic tests (c-statistics; goodness of fit, the probability of more accurately predicting the outcome than chance) were performed to calculate the discriminative ability of the regression models. For all tests, significance was defined at $\mathrm{p}<0.05$.

\section{Results}

After exclusion, a total of 8748 neurosurgery cases were included for analysis. The cases were subdivided into two cohorts based on resident involvement. Residents were present in 4529 cases.

In general the demographic profiles of the two cohorts were similar, with the exception of age and race. Patients in the resident cohort were significantly younger than those in the nonresident cohort $(57.6 \pm 15.1$ vs $56.0 \pm 15.0$ years, $\mathrm{p}<0.001)$. Patients in the resident cohort were less likely to be white $(79.5 \%$ vs $68.3 \%, \mathrm{p}<0.001)$ or black $(8.8 \%$ vs $6.8 \%, \mathrm{p}<0.001)$, but more likely to be "other" race $(10.1 \%$ vs $23.3 \%, \mathrm{p}<0.001)$. In contrast, comorbidities differed more markedly between the cohorts. Specifically, the resident cohort had a significantly lower proportion of patients with diabetes, history of smoking, dyspnea, and hypertension requiring medication, but a higher percentage of patients with ventilator dependence, history of disseminated cancer, history of steroid use for chronic conditions, and history of systemic sepsis $(\mathrm{p}<0.05)$ (Table 1). In addition, a significantly greater proportion of patients in the resident cohort underwent procedures classified as emergency cases and were assigned an advanced wound and ASA class. The residents were also more likely to be present in cases with greater total RVU ( $31.7 \pm 24.0$ vs $39.7 \pm 27.2$, p $<0.001)$ and longer operative time $(136.0 \pm 94.3$ vs 198.2 \pm 127.6 minutes, $\mathrm{p}<0.001$ ) (Table 2 ).

\section{Comparison of Outcomes}

The incidence of postoperative complications with respect to resident involvement is reported in Table 3. In our univariate analysis, resident presence in the operating room was associated with significantly higher rates of overall complication (OR 1.839; $11.2 \%$ vs $18.8 \%$, p < 0.001 ), surgical complication (OR $1.463 ; 1.9 \%$ vs $2.7 \%$, $\mathrm{p}=0.009$ ), and medical complication (OR 1.914; $9.9 \%$ vs $17.3 \%, p<0.001)$. Of the surgical complications, SSI was strongly associated with resident involvement $(\mathrm{p}=$ 0.007). Of medical complications, myocardial infarction, pneumonia, unplanned intubation, pulmonary embolism, ventilator $>48$ hours, cerebrovascular attack/stroke, coma $>24$ hours, postoperative transfusion, DVT, and sepsis/ septic shock were all significantly more frequent in cases with resident involvement. Moreover, the resident cohort had significantly higher rates of reoperation (OR 1.683; $3.2 \%$ vs $5.2 \%$, p < 0.001 ), mortality (OR $1.661 ; 1.4 \%$ vs $2.3 \%, \mathrm{p}=0.002$ ), and unplanned readmissions (OR 1.325; $5.4 \%$ vs $7.0 \%, \mathrm{p}=0.002$ ).

\section{Regression Analysis}

For each outcome of interest, multiple logistic regression models were constructed that adjusted for selected risk factors and propensity score (Table 4). Resident participation correlated with an increased, but not statistically significant, risk of complications. This was true for overall complication (OR 1.116, 95\% CI 0.961-1.297), surgical complication (OR 1.132, 95\% CI 0.825-1.554), medical complication (OR 1.146, 95\% CI 0.979-1.343), reoperation (OR $1.250,95 \%$ CI $0.984-1.589$ ), mortality (OR 1.164, 95\% CI 0.780-1.737), or unplanned readmission (OR 1.148, 95\% CI 0.946-1.393). The c-statistics test was used to demonstrate discriminability of these models. Multivariate analysis has also resulted in a substantial decrease in odds ratios for overall complication (1.839 vs 1.116), surgical complication (1.463 vs 1.132), medical complication (1.914 vs 1.146), reoperation (1.683 vs 1.250 ), mortality (1.661 vs 1.164), and unplanned readmission (1.325 vs 1.148$)$.

\section{Discussion \\ Study Rationale}

A plethora of current literature findings converge on the concept that resident participation during surgical procedures is generally safe. Supporting evidence is found across various specialties, which reported no differences in surgical outcomes when residents participated in cardiothoracic, general, gynecological, plastic, urological, and vascular surgery cases. $5,7,19,21,31,38,46$

In the field of neurosurgery, literature examining the association of resident involvement and postoperative incidence of complications is virtually absent. Morgan et al. analyzed 355 cases of small unruptured intracranial aneurysms to examine the effect of resident involvement. ${ }^{27}$ The results of this single-center study showed that resident participation did not result in increased complications. A similar study of 299 intracranial aneurysm repair cases demonstrated that the procedure can be safely delegated to trainees with careful supervision, without compromising surgical outcomes ${ }^{47}$ Last, Neal at al. investigated 28 minimal access transforaminal lumbar interbody fusion procedures done by a single resident, and suggested that this procedure can be safely performed in a training environment. ${ }^{29}$ However, these studies are limited by their small sample size and their narrow focus on relatively specialized procedures. Given the paucity and focused aspects of previous investigations, the goal of our study was to capture a broader range of neurosurgical cases for a more robust and generalized analysis of resident involvement in the neurosurgical setting.

\section{The ACS-NSQIP}

The NSQIP is a nationally validated, outcome-based database that offers performance information to identify 
TABLE 1. Demographic data and comorbidities in 8748 patients treated with neurosurgery in 2011, categorized by resident presence

\begin{tabular}{|c|c|c|c|c|c|}
\hline \multirow[b]{3}{*}{ Variable } & \multicolumn{4}{|c|}{ Resident Present } & \multirow[b]{3}{*}{ p Value } \\
\hline & \multicolumn{2}{|c|}{ No (4219 patients) } & \multicolumn{2}{|c|}{ Yes (4529 patients) } & \\
\hline & Value & $\%$ & Value & $\%$ & \\
\hline \multicolumn{6}{|l|}{ Demographic } \\
\hline Age in yrs, mean $\pm S D^{*}$ & $57.6 \pm 15.1$ & & $56.0 \pm 15.0$ & & $<0.001$ \\
\hline $\mathrm{BMI}$ in $\mathrm{kg} / \mathrm{m}^{2}$, mean $\pm \mathrm{SD}$ & $29.3 \pm 6.7$ & & $29.1 \pm 6.6$ & & 0.209 \\
\hline Sex & & & & & 0.231 \\
\hline Male & 2041 & $48.4 \%$ & 2249 & $49.7 \%$ & \\
\hline Female & 2178 & $51.6 \%$ & 2280 & $50.3 \%$ & \\
\hline Race $^{*}$ & & & & & $<0.001$ \\
\hline White & 3354 & $79.5 \%$ & 3094 & $68.3 \%$ & \\
\hline Black & 371 & $8.8 \%$ & 309 & $6.8 \%$ & \\
\hline Asian & 66 & $1.6 \%$ & 69 & $1.5 \%$ & \\
\hline Other & 428 & $10.1 \%$ & 1057 & $23.3 \%$ & \\
\hline \multicolumn{6}{|l|}{ Comorbidities } \\
\hline Diabetes* & 685 & $16.6 \%$ & 628 & $13.9 \%$ & 0.002 \\
\hline Current smoker* & 1074 & $26.0 \%$ & 1061 & $23.4 \%$ & 0.027 \\
\hline Dyspnea* & 339 & $8.2 \%$ & 308 & $6.8 \%$ & 0.027 \\
\hline Dependent FHS prior to op & 295 & $7.1 \%$ & 294 & $6.5 \%$ & 0.346 \\
\hline Ventilator dependent* & 50 & $1.2 \%$ & 128 & $2.8 \%$ & $<0.001$ \\
\hline COPD & 186 & $4.5 \%$ & 204 & $4.5 \%$ & 0.828 \\
\hline $\mathrm{CHF}<30$ days & 17 & $0.4 \%$ & 17 & $0.4 \%$ & 0.836 \\
\hline Hypertension* & 2053 & $49.7 \%$ & 2075 & $45.8 \%$ & 0.008 \\
\hline Acute renal failure & 5 & $0.1 \%$ & 10 & $0.2 \%$ & 0.248 \\
\hline On dialysis & 24 & $0.6 \%$ & 23 & $0.5 \%$ & 0.696 \\
\hline Disseminated cancer* & 118 & $2.9 \%$ & 293 & $6.5 \%$ & $<0.001$ \\
\hline Open wound/WI & 91 & $2.2 \%$ & 103 & $2.3 \%$ & 0.710 \\
\hline Steroid use ${ }^{*}$ & 204 & $4.9 \%$ & 380 & $8.4 \%$ & $<0.001$ \\
\hline$>10 \%$ weight loss in $<6$ mos & 43 & $1.0 \%$ & 56 & $1.2 \%$ & 0.337 \\
\hline Bleeding disorders* & 114 & $2.8 \%$ & 161 & $3.6 \%$ & 0.022 \\
\hline Systemic sepsis* & 80 & $1.9 \%$ & 198 & $4.4 \%$ & $<0.001$ \\
\hline
\end{tabular}

$\mathrm{BMI}=$ body mass index; $\mathrm{CHF}=$ congestive heart failure; $\mathrm{COPD}=$ chronic obstructive pulmonary disease; $\mathrm{FHS}=$ functional health status; $\mathrm{WI}=$ wound infection.

* Denotes significant difference between cohorts $(p<0.05)$.

areas for improvement and to assist surgeons in targeted decision making. Since its inception in 1994, the NSQIP has proven to be a useful resource for surgeons and hospitals in improving the quality of patient care and surgical outcomes, while decreasing costs. Patient information is abstracted from medical charts, operative logs, anesthesia records, patient interviews, and any other means necessary to augment data completeness. The ACS-NSQIP employs dedicated clinical reviewers at more than 250 private-sector, geographically diverse hospitals to collect large volumes of surgical case data (more than 400,000 cases in 2011 alone) in a standardized format, ensuring the integrity of both the external and internal validity of the NSQIP database. In addition, clinical reviewers complete comprehensive training programs and the NSQIP conducts interrater reliability audits regularly. Most recently, the interobserver disagreement was calculated at $1.96 \%$. $^{44}$

Previously published articles have reliably used the
NSQIP database to conduct large-scale, multicenter analysis to examine the impact of resident involvement on surgical outcomes in the fields of plastic, general, and vascular surgery. ${ }^{21,24}$ Although the NSQIP does not capture the extent of resident involvement in operating rooms, the present study investigates the impact of any degree of resident involvement on postoperative outcome by using a similar approach to previously published studies. ${ }^{21,24}$

\section{Impact of Resident Involvement on Postoperative Outcome}

Whereas univariate analysis showed significant differences in complications based on resident involvement, our multivariate analysis revealed that resident involvement was not associated with increased overall complications (OR 1.116, 95\% CI 0.961-1.297), surgical complications (OR 1.132, 95\% CI 0.825-1.554), medical complications (OR 1.146, 95\% CI 0.979-1.343), reoperation (OR 1.250, 
TABLE 2. Operative characteristics in 8748 patients treated with neurosurgery in 2011, categorized by resident presence

\begin{tabular}{|c|c|c|c|c|c|}
\hline \multirow[b]{3}{*}{ Operative Variable } & \multicolumn{4}{|c|}{ Resident Present } & \multirow[b]{3}{*}{$\mathrm{p}$ Value } \\
\hline & \multicolumn{2}{|c|}{ No (4219 patients) } & \multicolumn{2}{|c|}{ Yes (4529 patients) } & \\
\hline & Value & $\%$ & Value & $\%$ & \\
\hline Preop transfusion $>4$ U RBCs & 22 & $0.5 \%$ & 36 & $0.8 \%$ & 0.115 \\
\hline Emergency* $^{*}$ & 232 & $5.6 \%$ & 376 & $8.3 \%$ & $<0.001$ \\
\hline Wound class* & & & & & $<0.001$ \\
\hline 1, Clean & 4089 & $96.9 \%$ & 4267 & $94.2 \%$ & \\
\hline 2, Clean-contaminated & 68 & $1.6 \%$ & 117 & $2.6 \%$ & \\
\hline 3, Contaminated & 16 & $0.4 \%$ & 41 & $0.9 \%$ & \\
\hline 4, Infected & 46 & $1.1 \%$ & 104 & $2.3 \%$ & \\
\hline ASA class* & & & & & $<0.001$ \\
\hline Class 1, no disturbance & 207 & $5.0 \%$ & 154 & $3.4 \%$ & \\
\hline Class 2, mild disturbance & 1904 & $46.1 \%$ & 1676 & $37.0 \%$ & \\
\hline Class 3 , severe disturbance & 1825 & $44.2 \%$ & 2268 & $50.1 \%$ & \\
\hline Class 4 , life-threatening disturbance & 271 & $6.6 \%$ & 401 & $8.9 \%$ & \\
\hline Class 5, moribund & 10 & $0.2 \%$ & 20 & $0.4 \%$ & \\
\hline Total op time in min, mean $\pm S D^{*}$ & & & & & $<0.001$ \\
\hline Total RVU, mean \pm SD* & & & & & $<0.001$ \\
\hline
\end{tabular}

* Denotes significant difference between cohorts $(p<0.05)$.

95\% CI 0.984-1.589), mortality (OR 1.164, 95\% CI 0.7801.737), and unplanned readmission (OR 1.148, 95\% CI 0.946-1.393). However, importantly, none of the differences reached statistical significance.

These findings corroborate the results from previous studies in different surgical settings. Tseng et al. investigated outcomes in 37,907 patients who underwent elective general surgery and reported an increase in overall morbidity with resident participation (OR $1.14,95 \%$ CI 1.00 1.29); however, statistical significance was not reached when the patients were stratified by different procedures. ${ }^{46}$ A similar study was performed in 60,711 patients who underwent elective general surgery procedures. ${ }^{24}$ This study found elevated rates of overall complications with resident involvement (6.7\% vs $7.5 \%, \mathrm{p}<0.001)$, but there was no difference in mortality, reoperation, or severe complication rates. Raval et al. also demonstrated that resident participation is correlated with a modest $6.3 \%$ increase in morbidity for general and vascular surgeries, although adjusting for hospital-level variations effectively minimized any observed differences in complications due to resident involvement. ${ }^{38}$

\section{Multivariate Analyses and Confounding Factors}

In the present study, we evaluated resident involvement as an independent risk factor on postoperative outcomes. It is worthwhile to note, however, that due to the retrospective nature of this study, some of the clinically relevant variables were significantly different between the cohorts, thus potentially creating bias in our results. In particular, work RVU, often used as a proxy for procedural complexity, was $25.2 \%$ higher in the resident involvement cohort (39.7 \pm 27.2$)$ compared with the nonresident cohort (31.7 \pm 24.0 ). This observation could arise because the teaching hospitals where residents work are known to handle more rare and complex cases in their capacity as tertiary medical centers. ${ }^{23}$ Additionally, residents are often specifically recruited for "educational" cases that are more likely to be complex or nonroutine, which may have further contributed to differences in case complexity between the two cohorts. It is worthwhile to mention that an assumption that a higher RVU correlates with a more complex case is not always valid when examining the population consisting of a small sample size. To illustrate, the same RVUs are assigned to all craniotomies for meningioma regardless of the depth or routes of invasion. However, with a large enough sample size with heterogeneous case composition such as in our study (more than 8000 cases and 300 different procedure types), differences in RVUs become more relevant in determining procedural difficulties. Therefore, it is reasonable to assume that in our study, higher RVUs may be an indication of increasing procedural complexity.

Cases with higher RVU assignments have been reported to be correlated with higher complication rates. Multiinstitutional analyses of general and vascular surgeries based on the Veterans Affairs-NSQIP database found that increasing work RVU is correlated with increased risk of adverse cardiac events, respiratory failure, SSI, and venous thromboembolic events..$^{14,20,30,40}$ Our regression analysis substantiates this finding; a higher risk of overall and medical complications was observed in concordance with increasing RVU. Following the regression analysis, this baseline difference was adjusted, which resulted in a substantial decrease in odds ratios (Tables 3 and 4).

Average length of operation was also significantly longer for the resident cohort, with an average operative duration of 198.2 minutes compared with 136.0 minutes in the nonresident cohort. Although prolonged operative duration could be a direct result of resident education or inexperienced residents, it is also feasible that longer 
TABLE 3. Operative outcomes in 8748 patients treated with neurosurgery in 2011, categorized by resident presence

\begin{tabular}{|c|c|c|c|c|c|c|}
\hline \multirow[b]{3}{*}{ Outcome } & \multicolumn{5}{|c|}{ Resident Present } & \multirow[b]{3}{*}{ p Value } \\
\hline & \multicolumn{2}{|c|}{ No (4219 patients) } & \multicolumn{2}{|c|}{ Yes (4529 patients) } & \multirow[b]{2}{*}{ OR } & \\
\hline & Value & $\%$ & Value & $\%$ & & \\
\hline Overall complications & 471 & $11.2 \%$ & 850 & $18.8 \%$ & 1.839 & $<0.001$ \\
\hline \multicolumn{7}{|l|}{ Surgical complications } \\
\hline Any $\geq 1^{*}$ & 79 & $1.9 \%$ & 123 & $2.7 \%$ & 1.463 & 0.009 \\
\hline $\mathrm{SSI}^{*}$ & 74 & $1.8 \%$ & 118 & $2.6 \%$ & & 0.007 \\
\hline Wound dehiscence & 5 & $0.1 \%$ & 7 & $0.2 \%$ & & 0.649 \\
\hline Graft/prosthesis failure & 1 & $0.0 \%$ & 0 & $0.0 \%$ & & 0.482 \\
\hline \multicolumn{7}{|l|}{ Medical complications } \\
\hline Any $\geq 1^{*}$ & 416 & $9.9 \%$ & 784 & $17.3 \%$ & 1.914 & $<0.001$ \\
\hline Myocardial infarction* & 8 & $0.2 \%$ & 20 & $0.4 \%$ & & 0.037 \\
\hline Pneumonia* & 48 & $1.1 \%$ & 98 & $2.2 \%$ & & $<0.001$ \\
\hline Unplanned intubation* & 40 & $0.9 \%$ & 89 & $2.0 \%$ & & $<0.001$ \\
\hline Pulmonary embolism* & 18 & $0.4 \%$ & 34 & $0.8 \%$ & & 0.049 \\
\hline Ventilator $>48$ hrs $^{*}$ & 75 & $1.8 \%$ & 186 & $4.1 \%$ & & $<0.001$ \\
\hline Renal insufficiency & 7 & $0.2 \%$ & 8 & $0.2 \%$ & & 0.904 \\
\hline Acute renal failure & 2 & $0.0 \%$ & 6 & $0.1 \%$ & & 0.291 \\
\hline UTI & 88 & $2.1 \%$ & 98 & $2.2 \%$ & & 0.800 \\
\hline CVA/stroke* & 17 & $0.4 \%$ & 49 & $1.1 \%$ & & $<0.001$ \\
\hline Coma $>24 \mathrm{hrs}^{*}$ & 15 & $0.4 \%$ & 32 & $0.7 \%$ & & 0.025 \\
\hline Peripheral nerve injury & 5 & $0.1 \%$ & 5 & $0.1 \%$ & & 1.000 \\
\hline Cardiac arrest & 18 & $0.4 \%$ & 16 & $0.4 \%$ & & 0.582 \\
\hline Transfusions* & 208 & $4.9 \%$ & 464 & $10.2 \%$ & & $<0.001$ \\
\hline DVT $^{*}$ & 36 & $0.9 \%$ & 80 & $1.8 \%$ & & $<0.001$ \\
\hline Sepsis/septic shock* & 58 & $1.4 \%$ & 125 & $2.8 \%$ & & $<0.001$ \\
\hline \multicolumn{7}{|l|}{ Other } \\
\hline Reop* & 134 & $3.2 \%$ & 237 & $5.2 \%$ & 1.683 & $<0.001$ \\
\hline Death* & 60 & $1.4 \%$ & 106 & $2.3 \%$ & 1.661 & 0.002 \\
\hline Unplanned readmission* & 226 & $5.4 \%$ & 316 & $7.0 \%$ & 1.325 & 0.002 \\
\hline
\end{tabular}

operative time may be related to increasing procedural complexity, reflected by the higher RVUs of the cases in the resident cohort. In numerous studies, operative time has been recognized as a risk factor for adverse surgical outcomes. . $16,32,33,36,37,42,43,45$ Neurosurgery studies indicate that increased operative time is a significant risk factor for infections and cranial nerve injury following craniotomy and carotid endarterectomy, respectively. ${ }^{11,13,22,25}$ Thus, the differences in operative time between the two cohorts may explain some of the increase in complication rates with resident involvement prior to baseline adjustment.

Residents were also involved in cases involving patients skewed toward increased operative risk factors: advanced wound and ASA class. The association between these operative characteristics and surgical complications has been widely reported. In a study of 2249 neurosurgery patients, advanced wound class was associated with approximately $50 \%$ increased rates of sepsis $(9.1 \%$ vs $6.8 \%, \mathrm{p}<0.001){ }^{28}$ Furthermore, the National Nosocomial Infection Surveillance System collected surgical wound infection rates in 44 hospitals and reported that there was a consistent increase in infection rate of $2.1 \%, 3.3 \%, 6.4 \%$, and $7.1 \%$ with advancing wound class..$^{10} \mathrm{~A}$ study by Boakye et al. on 1560 corpectomy cases demonstrated that an ASA class greater than 3 was significantly associated with postoperative mortality (OR 6.93). ${ }^{6}$ Similarly, Cornu et al. reported that an ASA Class 3 score was a significant predictor $(\mathrm{p}<$ 0.001 ) for poorer surgical outcomes for intracranial meningioma in elderly patients. ${ }^{8}$

In our study, the proportion of patients with comorbidities was significantly different between the two cohorts. Because patients with more complex health conditions at baseline are more likely to experience postoperative complications, comorbidities selected from the univariate screening were controlled for in our multivariate analysis. Additionally, we attempted to further reduce patient bias by performing a propensity scoring analysis, which has been incorporated into our risk-adjusted model. Consequently, our multivariate analysis significantly reduced the differences in postoperative complication rates between the two cohorts. This has been demonstrated by a substantial decrease in odds ratios for 30-day postopera- 


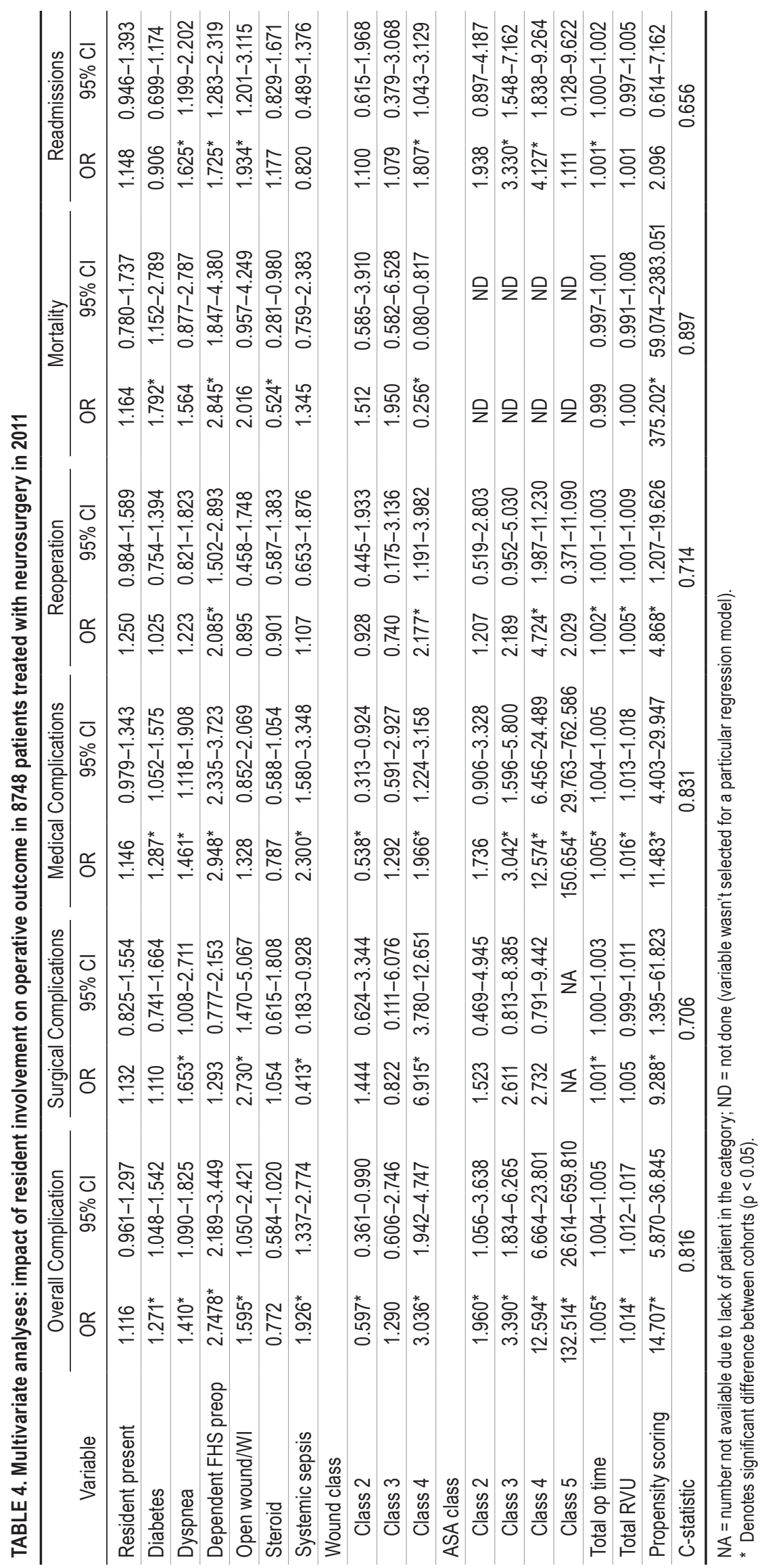


tive outcomes with resident involvement. The significant changes in odds ratios with risk adjustment show that much of the higher complication rates in the resident cohort were attributable to the baseline difference. Our regression analysis also demonstrated that resident involvement in the operating room is not a statistically significant factor in adverse postoperative outcomes.

\section{Study Limitations}

Our study is the first multicenter and statistically robust analysis that evaluates the impact of resident involvement in neurosurgery. However, our study is not without limitations. First, due to the nature of the retrospective study, the patient groups differed in a number of characteristics, which created both known and unknown confounding effects. Although we adjusted for these factors in our multivariate analysis, these biases cannot be fully eliminated. To illustrate, we attempted to control for the difference in case complexity by using RVUs, yet our risk adjustment could not account for the potentially uneven distribution of cases or hospital types. Second, there are limitations that are inherently related to the NSQIP database itself. The database does not capture the extent of resident participation in operative procedures or perioperative care of patients. The specialties of participating residents and their postgraduate year status are not recorded either. Our analysis is also limited to the variables tracked in the NSQIP. Although the database captures more than 240 clinical variables from 10 different surgical specialties, certain postoperative outcomes pertinent to neurosurgery (i.e., CSF leak rate, frontalis palsy, or other minor neurological complications) are not captured. Nevertheless, this multicenter database represents more than 300 neurosurgical procedure types, which greatly benefits the external validity of our study, especially when compared with previous single-center neurosurgery studies based on one procedure. Last, the NSQIP does not track complications occurring more than 30 days after the index operation, thus underrepresenting the long-term overall morbidity and mortality rates.

\section{Conclusions}

Resident surgeons are a critical component of the current health care system in providing invaluable services to academic medical centers and patients alike. Using a large, multicenter ACS-NSQIP database, we found that much of the difference in observed complication rates with resident involvement is attributable to other confounding factors and that resident participation is not a statistically significant, independent predictor of 30-day complication rates. Maintaining high standards in postgraduate training may help enhance patient care and reduce postoperative incidence of complications.

\section{References}

1. Advani V, Ahad S, Gonczy C, Markwell S, Hassan I: Does resident involvement effect surgical times and complication rates during laparoscopic appendectomy for uncomplicated appendicitis? An analysis of 16,849 cases from the ACSNSQIP. Am J Surg 203:347-352, 2012
2. American College of Surgeons: Data Collection, Analysis, and Reporting. (http://site.acsnsqip.org/program-specifics/ data-collection-analysis-and-reporting/)[Accessed November 29, 2014]

3. American College of Surgeons National Surgical Quality Improvement Program: User Guide for the 2011 Participant Use Data File. (http://site.acsnsqip.org/wp-content/ uploads/2012/03/2011-User-Guide_Final.pdf) [Accessed November 29, 2014]

4. Ball CG, Pitt HA, Kilbane ME, Dixon E, Sutherland FR, Lillemoe KD: Peri-operative blood transfusion and operative time are quality indicators for pancreatoduodenectomy. HPB (Oxford) 12:465-471, 2010

5. Baskett RJ, Buth KJ, Legaré JF, Hassan A, Hancock Friesen C, Hirsch GM, et al: Is it safe to train residents to perform cardiac surgery? Ann Thorac Surg 74:1043-1049, 2002

6. Boakye M, Patil CG, Ho C, Lad SP: Cervical corpectomy: complications and outcomes. Neurosurgery 63 (4 Suppl 2):295-302, 2008

7. Coates KW, Kuehl TJ, Bachofen CG, Shull BL: Analysis of surgical complications and patient outcomes in a residency training program. Am J Obstet Gynecol 184:1380-1385, 2001

8. Cornu P, Chatellier G, Dagreou F, Clemenceau S, Foncin JF, Rivierez M, et al: Intracranial meningiomas in elderly patients. Postoperative morbidity and mortality. Factors predictive of outcome. Acta Neurochir (Wien) 102:98-102, 1990

9. Cowles RA, Moyer CA, Sonnad SS, Simeone DM, Knol JA, Eckhauser FE, et al: Doctor-patient communication in surgery: attitudes and expectations of general surgery patients about the involvement and education of surgical residents. $\mathbf{J}$ Am Coll Surg 193:73-80, 2001

10. Culver DH, Horan TC, Gaynes RP, Martone WJ, Jarvis WR, Emori TG, et al: Surgical wound infection rates by wound class, operative procedure, and patient risk index. Am J Med 91(3B):152S-157S, 1991

11. Cunningham EJ, Bond R, Mayberg MR, Warlow CP, Rothwell PM: Risk of persistent cranial nerve injury after carotid endarterectomy. J Neurosurg 101:445-448, 2004

12. D'Agostino RB Jr: Propensity score methods for bias reduction in the comparison of a treatment to a non-randomized control group. Stat Med 17:2265-2281, 1998

13. Dashti SR, Baharvahdat H, Spetzler RF, Sauvageau E, Chang SW, Stiefel MF, et al: Operative intracranial infection following craniotomy. Neurosurg Focus 24(6):E10, 2008

14. Davenport DL, Ferraris VA, Hosokawa P, Henderson WG, Khuri SF, Mentzer RM Jr: Multivariable predictors of postoperative cardiac adverse events after general and vascular surgery: results from the patient safety in surgery study. $\mathbf{J}$ Am Coll Surg 204:1199-1210, 2007

15. Davenport DL, Henderson WG, Khuri SF, Mentzer RM Jr: Preoperative risk factors and surgical complexity are more predictive of costs than postoperative complications: a case study using the National Surgical Quality Improvement Program (NSQIP) database. Ann Surg 242:463-471, 2005

16. Dexter SP, Martin IG, Marton J, McMahon MJ: Long operation and the risk of complications from laparoscopic cholecystectomy. Br J Surg 84:464-466, 1997

17. Dillon P, Hammermeister K, Morrato E, Kempe A, Oldham $\mathrm{K}$, Moss L, et al: Developing a NSQIP module to measure outcomes in children's surgical care: opportunity and challenge. Semin Pediatr Surg 17:131-140, 2008

18. Henderson WG, Daley J: Design and statistical methodology of the National Surgical Quality Improvement Program: why is it what it is? Am J Surg 198 (5 Suppl):S19-S27, 2009

19. Jan A, Riggs DR, Orlando KL, Khan FJ: Surgical outcomes based on resident involvement: what is the impact on vascular surgery patients? J Surg Educ 69:638-642, 2012

20. Johnson RG, Arozullah AM, Neumayer L, Henderson WG, 
Hosokawa P, Khuri SF: Multivariable predictors of postoperative respiratory failure after general and vascular surgery: results from the patient safety in surgery study. J Am Coll Surg 204:1188-1198, 2007

21. Jordan SW, Mioton LM, Smetona J, Aggarwal A, Wang E, Dumanian GA, et al: Resident involvement and plastic surgery outcomes: an analysis of 10,356 patients from the American College of Surgeons National Surgical Quality Improvement Program database. Plast Reconstr Surg 131:763-773, 2013

22. Kanat A: Risk factors for neurosurgical site infections after craniotomy: a prospective multicenter study of 2944 patients. Neurosurgery 43:189-190, 1998

23. Khuri SF, Najjar SF, Daley J, Krasnicka B, Hossain M, Henderson WG, et al: Comparison of surgical outcomes between teaching and nonteaching hospitals in the Department of Veterans Affairs. Ann Surg 234:370-383, 2001

24. Kiran RP, Ahmed Ali U, Coffey JC, Vogel JD, Pokala N, Fazio VW: Impact of resident participation in surgical operations on postoperative outcomes: National Surgical Quality Improvement Program. Ann Surg 256:469-475, 2012

25. Korinek AM, Golmard JL, Elcheick A, Bismuth R, van Effenterre R, Coriat $\mathrm{P}$, et al: Risk factors for neurosurgical site infections after craniotomy: a critical reappraisal of antibiotic prophylaxis on 4,578 patients. Br J Neurosurg 19:155-162, 2005

26. Little RJ, Rubin DB: Causal effects in clinical and epidemiological studies via potential outcomes: concepts and analytical approaches. Annu Rev Public Health 21:121-145, 2000

27. Morgan MK, Assaad NN, Davidson AS: How does the participation of a resident surgeon in procedures for small intracranial aneurysms impact patient outcome? J Neurosurg 106:961-964, 2007

28. Narotam PK, van Dellen JR, du Trevou MD, Gouws E: Operative sepsis in neurosurgery: a method of classifying surgical cases. Neurosurgery 34:409-416, 1994

29. Neal CJ, Rosner MK: Resident learning curve for minimalaccess transforaminal lumbar interbody fusion in a military training program. Neurosurg Focus 28(5):E21, 2010

30. Neumayer L, Hosokawa P, Itani K, El-Tamer M, Henderson WG, Khuri SF: Multivariable predictors of postoperative surgical site infection after general and vascular surgery: results from the patient safety in surgery study. J Am Coll Surg 204:1178-1187, 2007

31. Nguyen CT, Babineau DC, Jones JS: Impact of urologic resident training on patient pain and morbidity associated with office-based cystoscopy. Urology 71:782-786, 2008

32. Nichols RL: Postoperative wound infection. N Engl J Med 307:1701-1702, 1982

33. Noordzij PG, Poldermans D, Schouten O, Bax JJ, Schreiner FA, Boersma E: Postoperative mortality in The Netherlands: a population-based analysis of surgery-specific risk in adults. Anesthesiology 112:1105-1115, 2010

34. Papandria D, Rhee D, Ortega G, Zhang Y, Gorgy A, Makary MA, et al: Assessing trainee impact on operative time for common general surgical procedures in ACS-NSQIP. J Surg Educ 69:149-155, 2012

35. Peduzzi P, Concato J, Kemper E, Holford TR, Feinstein AR: A simulation study of the number of events per variable in logistic regression analysis. J Clin Epidemiol 49:1373-1379, 1996

36. Pessaux P, Msika S, Atalla D, Hay JM, Flamant Y: Risk factors for postoperative infectious complications in noncolorec- tal abdominal surgery: a multivariate analysis based on a prospective multicenter study of 4718 patients. Arch Surg 138:314-324, 2003

37. Procter LD, Davenport DL, Bernard AC, Zwischenberger JB: General surgical operative duration is associated with increased risk-adjusted infectious complication rates and length of hospital stay. J Am Coll Surg 210:60-65, e1-e2, 2010

38. Raval MV, Wang X, Cohen ME, Ingraham AM, Bentrem DJ, Dimick JB, et al: The influence of resident involvement on surgical outcomes. J Am Coll Surg 212:889-898, 2011

39. Reeves JG, Kasirajan K, Veeraswamy RK, Ricotta JJ II, Salam AA, Dodson TF, et al: Characterization of resident surgeon participation during carotid endarterectomy and impact on perioperative outcomes. J Vasc Surg 55:268-273, 2012

40. Rogers SO Jr, Kilaru RK, Hosokawa P, Henderson WG, Zinner MJ, Khuri SF: Multivariable predictors of postoperative venous thromboembolic events after general and vascular surgery: results from the patient safety in surgery study. $\mathbf{J}$ Am Coll Surg 204:1211-1221, 2007

41. Scarborough JE, Pappas TN, Cox MW, Bennett KM, Shortell CK: Surgical trainee participation during infrainguinal bypass grafting procedures is associated with increased early postoperative graft failure. J Vasc Surg 55:715-720, 2012

42. Selim M: Perioperative stroke. N Engl J Med 356:706-713, 2007

43. Shapiro M, Muñoz A, Tager IB, Schoenbaum SC, Polk BF: Risk factors for infection at the operative site after abdominal or vaginal hysterectomy. N Engl J Med 307:1661-1666, 1982

44. Shiloach M, Frencher SK Jr, Steeger JE, Rowell KS, Bartzokis $\mathrm{K}$, Tomeh MG, et al: Toward robust information: data quality and inter-rater reliability in the American College of Surgeons National Surgical Quality Improvement Program. J Am Coll Surg 210:6-16, 2010

45. Tan TW, Kalish JA, Hamburg NM, Rybin D, Doros G, Eberhardt RT, et al: Shorter duration of femoral-popliteal bypass is associated with decreased surgical site infection and shorter hospital length of stay. J Am Coll Surg 215:512-518, 2012

46. Tseng WH, Jin L, Canter RJ, Martinez SR, Khatri VP, Gauvin J, et al: Surgical resident involvement is safe for common elective general surgery procedures. J Am Coll Surg 213:19-28, 2011

47. Woodrow SI, Bernstein M, Wallace MC: Safety of intracranial aneurysm surgery performed in a postgraduate training program: implications for training. J Neurosurg 102:616621,2005

\section{Author Contributions}

Conception and design: all authors. Acquisition of data: Lim, BD Kim. Analysis and interpretation of data: all authors. Drafting the article: Lim, Parsa, BD Kim, Rosenow. Critically revising the article: all authors. Reviewed submitted version of manuscript: JYS Kim, Lim. Approved the final version of the manuscript on behalf of all authors: JYS Kim. Statistical analysis: Lim, BD Kim. Administrative/technical/material support: JYS Kim, Lim. Study supervision: JYS Kim, Lim, Parsa, Rosenow.

\section{Correspondence}

John Y. S. Kim, Department of Surgery, Northwestern University, Feinberg School of Medicine, 675 N. St. Clair St., Galter Ste. 19-250, Chicago, IL 60611. email: jokim@nmh.org. 